\title{
Do low-carbon-emission diets lead to higher nutritional quality and positive health outcomes? A systematic review of the literature
}

\author{
Charlotte LR Payne, ${ }^{*}$, Peter Scarborough and Linda Cobiac
}

British Heart Foundation Centre on Population Approaches to Non-Communicable Disease Prevention, Nuffield Department of Population Health, University of Oxford, Old Road Campus, Headington, Oxford OX3 7LF, UK

Submitted 22 June 2015: Final revision received 5 January 2016: Accepted 17 February 2016: First published online 15 March 2016

\begin{abstract}
Objective: To evaluate what is known about the relative health impacts, in terms of nutrient intake and health outcomes, of diets with reduced greenhouse gas emissions (GHGE).

Design: We systematically reviewed the results of published studies that link GHGE of dietary patterns to nutritional content or associated consequences for health.

Setting: We included studies published in English in peer-reviewed journals that included data on actual and modelled diets and enabled a matched comparison of GHGE with nutrient composition and/or health outcomes.

Subjects: Studies included used data from subjects from the general population, who had taken part in dietary surveys or prospective cohort studies.

Results: We identified sixteen eligible studies, with data on 100 dietary patterns. We present the results as dietary links between GHGE reduction and impact on nutrients to limit ( $n$ 151), micronutrient content ( $n$ 158) and health outcomes ( $n$ 25). The results were highly heterogeneous. Across all measures of 'healthiness', 64\% ( $n$ 214) of dietary links show that reduced GHGE from diets were associated with worse health indicators. However, some trends emerged. In particular, reduced saturated fat and salt are often associated with reduced GHGE in diets that are low in animal products (57/84). Yet these diets are also often high in sugar (38/55) and low in essential micronutrients (129/158).

Conclusions: Dietary scenarios that have lower GHGE compared with average consumption patterns may not result in improvements in nutritional quality or health outcomes. Dietary recommendations for reduced GHGE must also address sugar consumption and micronutrient intake.
\end{abstract}

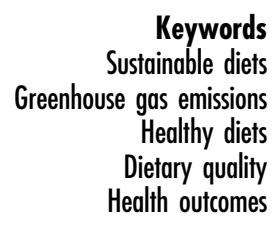

Climate change is predicted to exacerbate many of the major public health problems facing the world today ${ }^{(1)}$ and has been linked to increasing anthropogenic greenhouse gas emissions $(\mathrm{GHGE})^{(2)}$. Although estimates of the environmental impact of the food system vary based on methodological considerations, in developed countries it has been estimated that between 15 and $28 \%$ of all GHGE are due to patterns of food consumption ${ }^{(3)}$. The food system is also thought to be the primary global driver of the increasing double burden of obesity and malnutrition $^{(4)}$.

Currently, strategies to combat the rise of diet-related disease in the developed world focus on manipulating the food environment to increase purchasing of 'healthy' foods and decrease purchasing of 'unhealthy' foods. Examples of interventions include food labelling ${ }^{(5)}$, food taxes ${ }^{(6)}$, advertising restrictions $^{(7)}$ and food reformulation ${ }^{(8)}$.
Similar manipulations of the food environment could be applied to promote consumption of foods associated with lower GHGE, in order to lead to more sustainable dietary patterns ${ }^{(9)}$. It has been suggested that many of the nutrients currently associated with health risks are also high in foods associated with high environmental impact and therefore switching to a 'healthy' diet may also contribute to reductions in $\mathrm{GHGE}^{(10)}$.

Recently, three reviews have been published that summarize current literature on the relationship between the health and environmental impacts of dietary patterns. Joyce et al. found that results were inconsistent, but that higher levels of plant and plant-based foods were generally associated with both positive health outcomes and diet-related $\mathrm{GHGE}^{(11)}$. Hallstrom et al. had similarly mixed results, finding that dietary changes proposed specifically for health reasons had the potential to reduce 
up to $50 \%$ of diet-related $\mathrm{GHGE}^{(12)}$. Auestad and Fulgoni included studies that addressed other aspects of environmental impact as well as GHGE and also found overall heterogeneity in the results of studies ${ }^{(13)}$. Thus we undertook a review that aimed to summarize the findings in the literature and combine the results to allow for an assessment of the weight of evidence regarding healthy, sustainable diets.

\section{Objectives}

The objective of the present literature review was to identify studies that have reported changes in GHGE and changes in either nutritional components or health outcomes as a result of variation in actual or modelled consumption patterns, and to use these data to answer the following research questions:

1. Are low-GHGE dietary patterns associated with reduced CVD and cancer incidence or mortality?

2. Are low-GHGE dietary patterns associated with reduced saturated fat, sugar or salt consumption?

3. Are low-GHGE dietary patterns associated with increased micronutrient consumption?

Additionally, we used the results to assess whether associations between GHGE and health/nutrition outcomes vary by level of meat consumption in the lowGHGE dietary patterns.

\section{Methods}

We used several sources to search peer-reviewed, published literature reporting the results of the following types of study: (i) prospective cohort studies, in which baseline diet groups are defined by dietary GHGE; (ii) cross-sectional dietary surveys (e.g. national surveys of patterns of food consumption; baseline surveys for observational or experimental studies), which use cluster analysis to identify dietary patterns with differing levels of GHGE; and (iii) crosssectional nutritional surveys that are used to model potential diets with differing levels of GHGE. We included only studies for which quantitative data on GHGE and dietary nutritional content or health outcomes were available.

We searched the reference lists of the three previously published reviews on this topic ${ }^{(11-13)}$. We also searched the citations of these articles using Google Scholar.

We searched PubMed, Web of Science and Scopus in October 2015 using the following search strategy:

(GHG* OR greenhouse gas emission* OR environmental impact OR sustainab*) AND (diet*) AND (nutrition* OR health*)

This search was applied to the fields Title (PubMed), Article title/abstract/keywords (Scopus) and Title (Web of Science). In PubMed, we limited our search to journal articles focusing on human populations between 2000 and present. In Scopus, we limited our search to include journal articles only. We limited our results to Englishlanguage publications with medium to high relevance to the query and to those with a publication date between 2005 and present.

We searched the Food Climate Research Network (FCRN) research library (http://www.fcrn.org.uk/researchlibrary) in May 2015 using the keyword 'sustainable healthy diets'.

We scanned the title and abstract of all studies selected by these four searches to determine their suitability for inclusion in the present review. We included studies that:

1. evaluated the diet as a whole (excluding alcohol);

2. evaluated actual or modelled diets, including those based on dietary recommendations; and

3. included quantitative data expressing the GHGE and nutrient content and/or health outcomes of diets.

We excluded studies that:

1. were not articles published in peer-reviewed journals;

2. evaluated only separate food groups within a diet;

3. did not enable a direct matched comparison (e.g. reported GHGE for individual food groups within a diet and nutritional data for the diet as a whole); and

4. used a measure other than GHGE to estimate environmental impact, without giving GHGE data.

We extracted data on macro- and micronutrients that have been associated with 'healthy' or 'unhealthy' diets. Sugar, salt and saturated fat are the three nutrients identified by the WHO as important to limit in order to achieve a healthy diet associated with reduced non-communicable disease $^{(14)}$. The $\mathrm{WHO}$ also recommends reductions in the consumption of trans fats, which were not included in the current analysis as trans fat reductions are generally achieved at the industrial stage rather than by changes in diet. Although many micronutrients are considered important for health, previous research has shown that meat production is responsible for a large proportion of dietary carbon emissions ${ }^{(15)}$; therefore we extracted data on micronutrients that have been highlighted as potentially deficient in a low-meat diet ${ }^{(16)}$.

We used a modified QUADAS-2 tool ${ }^{(17)}$ to assess the risk of bias in individual studies. The details of the questions developed for this tool are shown in Table 1.

We deemed the results inappropriate for a formal metaanalysis due to the heterogeneity of study designs and dietary scenarios that were compared. We grouped the studies based on the health outcome and/or nutrient being measured and conducted a sign test to evaluate whether each dietary comparison answered the three research questions positively or negatively.

The full protocol for this search was published on Prospero (registration number CRD42015027360). 
Table 1 The modified QUADAS-2 tool used to identify risk of bias within individual studies and to inform the presentation of data and analysis of results

\begin{tabular}{|c|c|c|c|}
\hline Domains & Selection of control/baseline diet & Selection of comparator diets & Selection of GHGE data \\
\hline Description & $\begin{array}{l}\text { Describe control/baseline diet, if } \\
\text { applicable } \\
\text { Describe rationale for the selection of } \\
\text { the control/baseline diet }\end{array}$ & $\begin{array}{l}\text { Describe the rationale for the selection } \\
\text { of comparator diets } \\
\text { Describe the comparator diets } \\
\text { If modelled, describe the assumptions/ } \\
\text { constraints used }\end{array}$ & $\begin{array}{l}\text { Describe the rationale for the } \\
\text { selection of GHGE data } \\
\text { Describe the GHGE data source }\end{array}$ \\
\hline $\begin{array}{l}\text { Signalling } \\
\text { questions }\end{array}$ & $\begin{array}{l}\text { Is there a control/baseline } \\
\text { diet? } \\
\text { What population is the control/ } \\
\text { baseline diet based on? }\end{array}$ & $\begin{array}{l}\text { Are comparator diets actual or } \\
\text { modelled? } \\
\text { If modelled, what assumptions/constraints } \\
\text { are used? } \\
\text { What populations are the comparator } \\
\text { diets based on? } \\
\text { Are comparator diets determined (directed) } \\
\text { by GHGE or nutritional constraints? }\end{array}$ & $\begin{array}{l}\text { From what source is GHGE } \\
\text { data selected? } \\
\text { Is it directly relevant to the selected } \\
\text { diets? }\end{array}$ \\
\hline Risk of bias & $\begin{array}{l}\text { Could the selection of the control/ } \\
\text { baseline diet have introduced bias? }\end{array}$ & $\begin{array}{l}\text { Could the basis of comparator diets } \\
\text { have introduced bias? } \\
\text { Could the determination (direction) of } \\
\text { comparator diets have introduced bias? }\end{array}$ & $\begin{array}{l}\text { Could the selection (source) of } \\
\text { GHGE data have introduced bias? }\end{array}$ \\
\hline $\begin{array}{l}\text { Concerns } \\
\text { about } \\
\text { applicability }\end{array}$ & $\begin{array}{l}\text { Is the control/baseline diet relevant to } \\
\text { the review question(s)? }\end{array}$ & $\begin{array}{l}\text { Are the comparator diets relevant } \\
\text { to the review question(s)? }\end{array}$ & $\begin{array}{l}\text { Are the GHGE data used relevant } \\
\text { to the review question(s)? }\end{array}$ \\
\hline
\end{tabular}

GHGE, greenhouse gas emissions.

\section{Results}

\section{Description of included studies}

Figure 1 illustrates the results of our search strategy. We screened the title and abstracts of 2027 entries from four databases (FCRN Research Library, PubMed, Web of Science and Scopus) and three reference lists. From these, we identified sixteen studies ${ }^{(18-33)}$ that present data linking GHGE and nutritional information or health outcomes of 100 dietary patterns and yielding data on 346 cases of effects on nutritional quality or health outcomes of reduced-GHGE diets.

Table 2 details the studies included in the current review. Five studies used cluster analysis of actual diets and the remaining eleven studies used dietary modelling. The direction of the analysis, and the populations and markets represented by the dietary and GHGE data were identified by the QUADAS-2 tool to be potential sources of bias. Only one study was judged not to be at risk of bias, since it used aggregated data from populations and markets worldwide ${ }^{(21)}$. All others used data from a single country ( $n$ 14) or continent $(n 1)$, which may produce results that are not necessarily relevant in a global context.

Six studies were also judged to be at risk of further bias due to incomplete information regarding the source of GHGE data ( $n$ 4) or to GHGE data sourced from a market that was not geographically congruent with the source of dietary data $(n 2)$. Finally, the direction of the studies whether they chose or grouped diets according to GHGE, nutritional indices or other measures - may introduce bias. The majority of studies in the review used nutritional criteria to group or model diets ( $n$ 12); others used GHGE ( $n 1)$, price $(n 1)$ or a combination of criteria $(n 3)$.
In total, the results of the review yield data on 334 dietary links between GHGE and health measures, from 100 dietary scenarios reported in sixteen studies. The number of diets evaluated in each study ranged from two to sixteen.

Table 2 also summarizes the results of each study. Five studies reported on health outcomes, thirteen studies reported on macronutrient content of diets and six studies reported on micronutrient content of diets. Overall, $64 \%$ ( $n$ 214) of dietary patterns showed an association between reduced GHGE from diets and worse health indicators.

\section{Strength of associations between greenbouse gas emissions of diets and bealth indicators}

The units representing both GHGE and health indicators were heterogeneous between studies, as was the reporting of data for a baseline and/or contemporary diet. This meant that the studies are not directly comparable in terms of reporting the strength of association between GHGE and health indicators of dietary patterns, only the direction. Therefore we represent the 'strength' of associations reported in different studies by acknowledging the number of dietary patterns that corresponded to a positive or negative association between reduced GHGE and improved health indicators (Table 2).

\section{Association between greenhouse gas emissions of diets and bealth outcomes}

Five studies reported the GHGE and health outcomes of $\operatorname{diets}^{(18,20,21,24,28)}$. Of these, two were based on reduced meat and/or dairy consumption and found consistent association between reduced GHGE and positive 


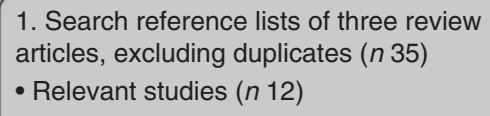

Reasons for exclusion:

- No measures of health outcomes/nutrient content of diets ( $n$ 12)

- GHGE data and health data not based on directly equivalent diets $(n 1)$

- Not peer-reviewed ( $n 1)$ - Based on non-GHGE environmental factors ( $n$ 10)

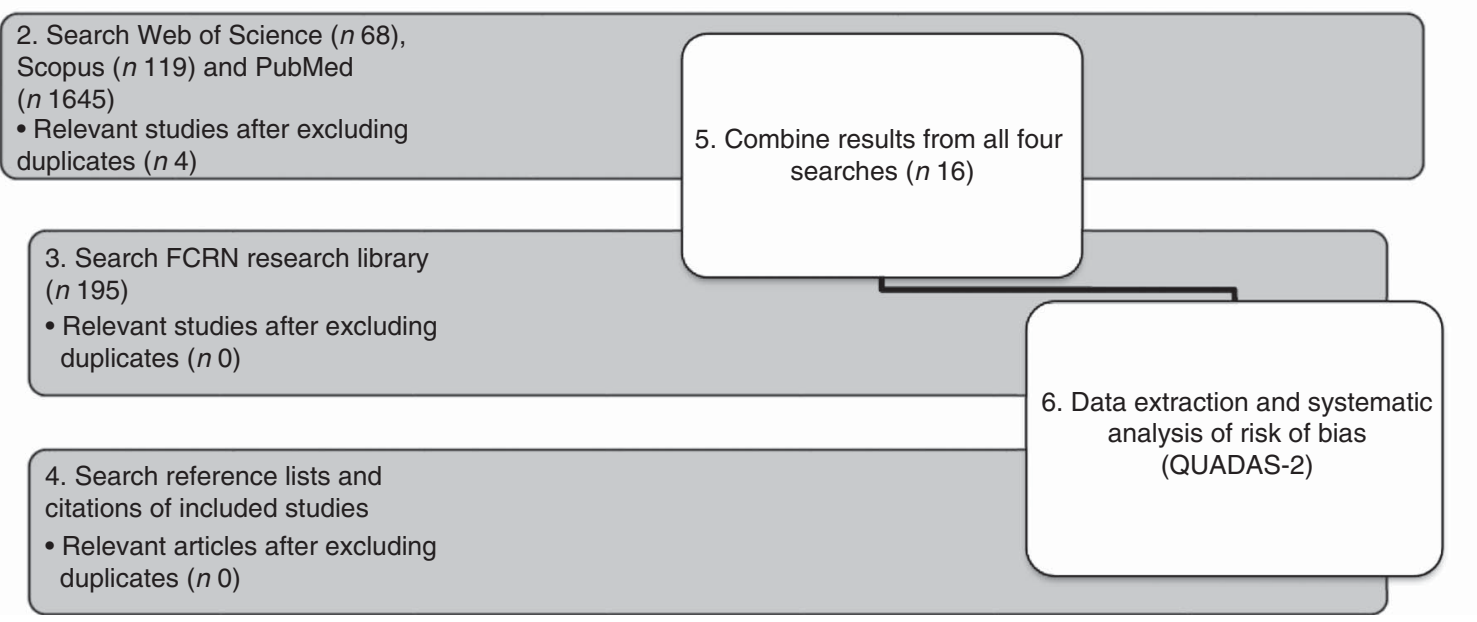

Fig. 1 The search process employed in the present review (GHGE, greenhouse gas emissions; FCRN, Food Climate Research Network)

health outcomes ${ }^{(20,21)}$. However, the remaining three studies $^{(18,24,28)}$ looked at diets based on cost, emissions and a combination of nutrition and GHGE, respectively, and found either an inconsistent relationship between GHGE and health outcomes or that low-GHGE diets were associated with increased risk from non-communicable disease. Of the twenty-five dietary scenarios compared, twelve showed positive health outcomes for the lower-GHGE diets (see online supplementary material, Table S1).

\section{Association between greenbouse gas emissions of diets and macronutrient content}

Thirteen studies reported the GHGE and macronutrient content of diets ${ }^{(19,22-33)}$. Six studies, five of which were modelled based on health or meat content ${ }^{(25,26,30-33)}$ and one on tax scenarios ${ }^{(24)}$, found that diets with lower GHGE also had a consistently lower saturated fat content. While no study found a consistent relationship between lower GHGE and lower salt or sugar content of the diets that they evaluated, four studies found that lower-GHGE diets were consistently associated with elevated levels of salt $^{(18,32)}$ and sugar ${ }^{(19,22,32)}$. A further four studies found that while some diets with lower GHGE had a reduced sugar or salt content, other diets within the same study were high in one or both of these nutrients ${ }^{(22,23,27-29,33)}$. Of 151 dietary comparisons across all studies, seventynine showed reduced levels of nutrients to limit for lowerGHGE diets, including twenty-seven out of forty-one for saturated fat, thirty-five out of fifty-five for salt, and seventeen out of fifty-five for sugar (see online supplementary material, Table S2).

\section{Association between greenbouse gas emissions of diets and micronutrient content}

Six studies reported the GHGE and micronutrient content of diets. Three studies found reduced micronutrient content in lower-GHGE diets for every micronutrient considered $^{(18,24,25)}$. Three studies ${ }^{(22,28,33)}$ found that in some lower-GHGE diets, Fe, Zn, vitamin A (thirty-three only) and vitamin $\mathrm{B}_{12}$ content were higher than in a higher-GHGE diet. Overall, of 158 dietary comparisons, 129 showed lower levels of essential micronutrients in lower-GHGE diets (see online supplementary material, Table S3).

\section{Discussion}

The current review presents an overview of published quantitative data that indicate whether there is an association between the health and environmental impact of actual and modelled dietary patterns.

We found highly inconsistent results regarding links between reduced GHGE and reduced content of nutrients to limit. In the cases of salt and saturated fat, the majority of dietary patterns found a reduction in levels of these nutrients in diets with reduced GHGE (twenty-nine of forty-three diets for salt, twenty-seven of forty-one diets for saturated fat). This may be due to the reduction in meat consumption in lower-GHGE dietary patterns. Of the twelve studies that reported salt and saturated fat content of diets, eight analysed diets with reduced levels of meat and dairy. However, the majority of dietary patterns that reported sugar intake showed increased sugar in lowerGHGE diets (thirty-eight of fifty-five diets). The reasons for this are unclear. 
Table 2 Details of the sixteen studies included in the present review, including aspects identified as presenting a potential risk of bias, and the results of each study

\begin{tabular}{|c|c|c|c|c|c|c|c|}
\hline \multirow{2}{*}{$\begin{array}{l}\text { Authors, date, } \\
\text { reference }\end{array}$} & \multirow[b]{2}{*}{ Study design } & \multirow[b]{2}{*}{ Direction of analysis } & \multirow{2}{*}{$\begin{array}{l}\text { Population represented by } \\
\text { dietary data }\end{array}$} & \multirow{2}{*}{$\begin{array}{l}\text { Market represented } \\
\text { by GHGE data }\end{array}$} & \multicolumn{3}{|c|}{ Results: direction of association between reduced GHGE and 'healthiness' of diets" } \\
\hline & & & & & Macronutrients $\dagger$ & Micronutrients $\ddagger$ & Health outcomes§ \\
\hline $\begin{array}{l}\text { Biesbroek et al. } \\
\quad(2014)^{(18)}\end{array}$ & Cluster analysis & GHGE & Netherlands (EPIC-NL cohort) & $\begin{array}{l}\text { Netherlands (LCA data provided by Blonk } \\
\text { Consultants) }\end{array}$ & & & $\begin{array}{l}\text { CVD risk: }--- \\
\text { Cancer incidence: }+-+ \\
\text { Mortality: }---\end{array}$ \\
\hline $\begin{array}{l}\text { Scarborough } \\
\text { et al. } \\
(2014)^{(19)}\end{array}$ & Cluster analysis & $\begin{array}{l}\text { Nutrition: levels of } \\
\text { meat/dairy }\end{array}$ & UK (EPIC-Oxford cohort study) & $\begin{array}{l}\text { UK (published data weighted by FAO } \\
\text { import/export data }\end{array}$ & $\begin{array}{l}\text { Saturated fat: }+++++ \\
\text { Total sugar: }-----\end{array}$ & & \\
\hline $\begin{array}{l}\text { Soret et al. } \\
\quad(2014)^{(20)}\end{array}$ & Cluster analysis & $\begin{array}{l}\text { Nutrition: levels of } \\
\text { meat/dairy }\end{array}$ & US (Adventist Health Study 2) & $\begin{array}{l}\text { USA, California (LCA and published GHGE } \\
\text { values) }\end{array}$ & & & Mortality: ++ \\
\hline $\begin{array}{l}\text { Tilman and } \\
\text { Clark } \\
(2014)^{(21)}\end{array}$ & Cluster analysis & $\begin{array}{l}\text { Nutrition: levels of } \\
\text { meat/dairy }\end{array}$ & $\begin{array}{l}\text { Global (publications of cohort } \\
\text { studies adhering to quality } \\
\text { criteria and evaluating health } \\
\text { outcomes of diets) }\end{array}$ & $\begin{array}{l}\text { Global (120 publications with } 555 \text { LCA of } \\
\text { GHGE of } 82 \text { different food items) }\end{array}$ & & & $\begin{array}{l}\text { Cancer incidence: }+++ \\
\text { Mortality: }++-\end{array}$ \\
\hline $\begin{array}{l}\text { Vieux et al. } \\
\quad(2013)^{(22)}\end{array}$ & Cluster analysis & $\begin{array}{l}\text { Nutrition: 'nutritional } \\
\text { quality' }\end{array}$ & $\begin{array}{l}\text { France (Individual and National } \\
\text { Survey on Food } \\
\text { Consumption) }\end{array}$ & $\begin{array}{l}\text { France (LCA provided by environmental } \\
\text { consultants) }\end{array}$ & $\begin{array}{l}\text { Saturated fat: }------ \\
\text { Sugar: }------ \\
\text { Salt: }-+++++\end{array}$ & $\begin{array}{l}\text { Fe: }+----- \\
\text { Zn: }+++--- \\
\text { Vit } A:------ \\
\text { Ca: }------- \\
\text { Vit } B_{12}:+----- \\
\text { lodine: }------- \\
\text { Riboflavin: }------\end{array}$ & \\
\hline $\begin{array}{l}\text { Berners-Lee } \\
\text { et al. } \\
(2012)^{(23)}\end{array}$ & Modelling & $\begin{array}{l}\text { Nutrition: levels of } \\
\text { meat/dairy }\end{array}$ & $\begin{array}{l}\text { UK (National Diet and Nutrition } \\
\text { Survey); US data used to } \\
\text { inform modelled diets }\end{array}$ & UK (published LCA data) & $\begin{array}{l}\text { Sugar: }-----+ \\
\text { Salt: }+++++-\end{array}$ & & \\
\hline $\begin{array}{l}\text { Briggs et al. } \\
\quad(2013)^{(24)}\end{array}$ & Modelling & Price & $\begin{array}{l}\text { UK (Living Costs and Food } \\
\text { Survey 2010) }\end{array}$ & UK (published data) & $\begin{array}{l}\text { Saturated fat: ++ } \\
\text { Salt: }--\end{array}$ & $\begin{array}{l}\text { Fe: }- \\
\mathrm{Zn}:-- \\
\mathrm{Ca}:-- \\
\text { Vit } \mathrm{B}_{12}:-\end{array}$ & CVD risk: -+ \\
\hline $\begin{array}{l}\text { Hallström et al. } \\
\qquad(2014)^{(25)}\end{array}$ & Modelling & $\begin{array}{l}\text { Nutrition: levels of } \\
\text { meat/dairy }\end{array}$ & Sweden (national statistics) & Sweden (published LCA data) & Saturated fat: ++ & $\begin{array}{l}\text { Fe: }-- \\
\text { Zn: }--\end{array}$ & \\
\hline $\begin{array}{l}\text { Hendrie et al. } \\
\qquad(2014)^{(26)}\end{array}$ & Modelling & $\begin{array}{l}\text { Nutrition: dietary } \\
\text { guidelines }\end{array}$ & $\begin{array}{l}\text { Australia (Australian National } \\
\text { Nutrition Survey) }\end{array}$ & $\begin{array}{l}\text { Australia (Multi Regional Input-Output } \\
\text { model using national input-output tables } \\
\text { and Australian national greenhouse gas } \\
\text { inventory) }\end{array}$ & Saturated fat: + & $\begin{array}{l}\text { Zn: }-- \\
\text { Ca }-- \\
\text { Vit A: - }\end{array}$ & \\
\hline $\begin{array}{l}\text { Hoolohan et al. } \\
\qquad(2013)^{(27)}\end{array}$ & Modelling & $\begin{array}{l}\text { Environmental } \\
\text { impact reduction; } \\
\text { meat reduction }\end{array}$ & $\begin{array}{l}\text { UK (National Diet and Nutrition } \\
\text { Survey) }\end{array}$ & UK (published LCA data) & $\begin{array}{l}\text { Sugar: }+++++----- \\
\text { Salt: }++++++---\end{array}$ & & \\
\hline $\begin{array}{l}\text { Milner et al. } \\
\quad(2015)^{(28)}\end{array}$ & Modelling & Nutrition and GHGE & $\begin{array}{l}\text { UK (National Diet and Nutrition } \\
\text { Survey) }\end{array}$ & Geographic source unclear & Salt: ++++++------ & $\begin{array}{l}\text { Fe: }++++++++++++ \\
\text { Ca: }------------ \\
\text { Vit } B_{12}:------------\end{array}$ & Cancer: ++---- \\
\hline
\end{tabular}




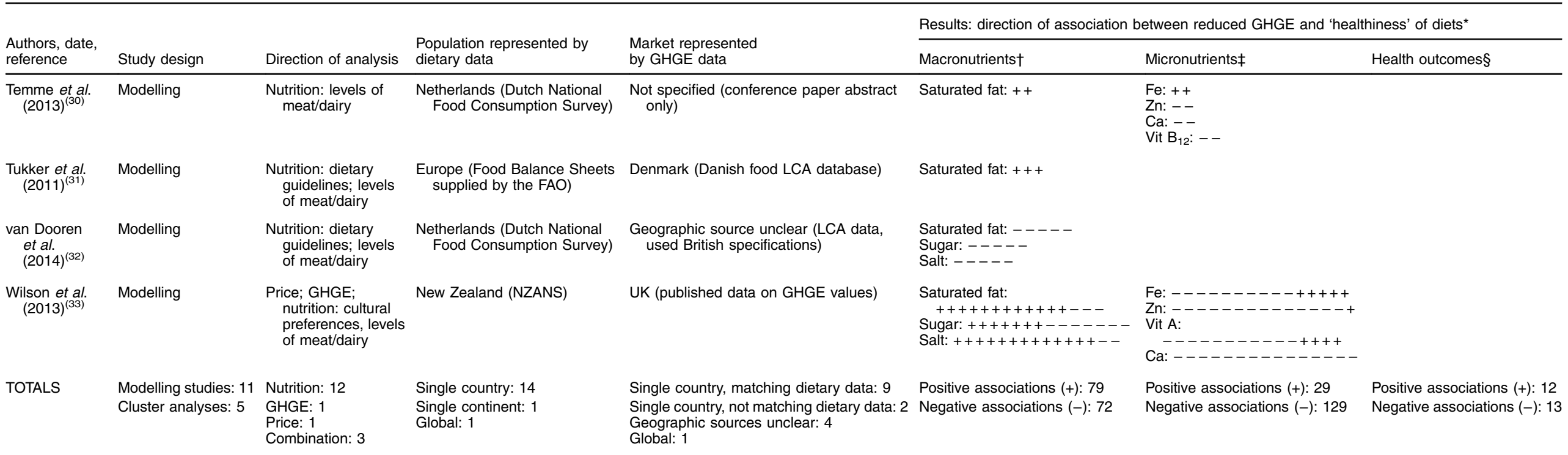

GHGE, greenhouse gas emissions; EPIC, European Prospective Investigation into Cancer and Nutrition; NZANS, New Zealand Adult Nutrition Survey; LCA, life cycle analysis; Vit, vitamin.

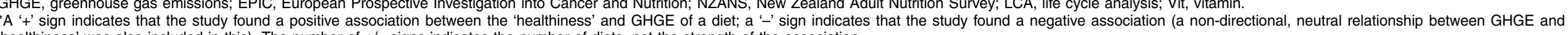
'healthiness' was also included in this). The number of $+/$-signs indicates the number of diets, not the strength of the association.

TA positive association was considered to be an association between reduced GHGE and reduced quantity of these macronutrients in the diet.

$\mp$ A positive association was considered to be an association between reduced GHGE and increased quantity of these micronutrients in the diet.

$\S A$ positive association was considered to be an association between reduced GHGE and reduced number of/risk of deaths, as represented by each diet. 
We also found an inconsistent relationship between reduced GHGE and positive health outcomes. Overall mortality was associated with four higher-GHGE diets and four lower-GHGE diets. Cancer was similarly inconsistent, with increased incidence in five reduced-GHGE diets and decreased incidence in seven reduced-GHGE diets. CVD risk was assessed by only two studies, and within these this disease was higher in low-GHGE diets in four out of five scenarios.

However, we did find that decreased micronutrient content of diets was more frequently associated with reduced GHGE than increases in micronutrient content, with far more cases in which lower-GHGE diets were associated with decreases in key micronutrients ( $n$ 129) than with increases in micronutrients ( $n$ 29). In particular, no study reported an increase in dietary $\mathrm{Ca}$ (thirty-nine showed decreased $\mathrm{Ca}$ ), and only one study reported an increase in dietary vitamin $\mathrm{B}_{12}$ (twenty showed decreased vitamin $\mathrm{B}_{12}$ ), with reduced-GHGE diets. Similarly to the negative associations discussed between key macronutrients, this is likely to be due to the decreased consumption of animal and particularly dairy products in diets with lower GHGE. Of the seven studies that reported micronutrient content of diets, three analysed diets with reduced levels of meat and dairy.

Fe was the only micronutrient for which dietary associations between an increase in micronutrient level and a reduction of GHGE were very slightly predominant (twenty of thirty-eight diets), but the reasons for this are unclear as the studies for which this is the case did not report $\mathrm{Fe}$ content of separate food groups ${ }^{(28,30,33)}$. Zn levels, in contrast, were lower in reduced-GHGE diets in twenty-five of twenty-nine scenarios.

These results clearly indicate micronutrients as a key area for concern in advocating reduced-GHGE diets. Health problems related to micronutrient deficiency are currently increasing worldwide ${ }^{(34)}$ and future research and policy should take measures to ensure that environmentally focused dietary recommendations do not neglect micronutrient recommendations.

For all associations, there were no clear differences between studies using cluster analysis and those using dietary modelling; instead, both study designs yield comparably heterogeneous results.

There are two main limitations of the present review. The first is the unrepresentative nature of published data. All studies use dietary data from countries in which the majority of the population is likely to follow a Western diet, although one study did include several 'Asian' $\operatorname{diets}^{(33)}$. The majority of studies also model diets based on their perceived 'healthiness' according to nutritional criteria, thus biasing the data towards healthier dietary patterns. Future studies could eliminate the nature of this bias by modelling diets based on known patterns of dietary change resulting from health interventions.

Three review articles that ask similar a question to the current study have been published recently ${ }^{(11-13)}$. Both
Joyce et $a l^{(11)}$ and Hallstrom et al. ${ }^{(12)}$ reviewed the evidence for the environmental impacts of dietary change, finding an inconsistency in associations between health and GHGE of dietary patterns and heterogeneity in study designs. Auestad and Fulgoni ${ }^{(13)}$ reviewed the literature linking dietary patterns to all aspects of the environmental impact of diets, and to economics, and found that heterogeneity in study designs and data sources prevented useful data assimilation. In the current study we asked whether diets with reduced carbon emissions are conducive to good health. Similarly to Auestad and Fulgoni, we also found that heterogeneity of data sources meant we could not assimilate data in order to assess the strength of associations, but we did find that results were highly inconsistent even when grouped by study design. We also found inconsistencies between markers of the 'healthiness' of diets and reduced GHGE.

We presented and discussed the results of our review based on the health measures considered in each study: health outcomes, nutrients to limit and essential micronutrients. This revealed that while lower-GHGE patterns show no consistent relationship with reduced nutrients to limit or positive health outcomes, many do show a correlation with reductions in micronutrient intake and with elevated sugar levels. We conclude that the maintenance of sufficient micronutrients in the diet, and the control of sugar levels, should be key concerns for policy makers advocating environmentally sustainable diets.

\section{Acknowledgements}

Financial support: This review was funded by the Department for the Environment, Food and Rural Affairs (grant number FO0318) and the Biotechnology and Biological Sciences Research Council as a contribution to the European Commission SUSFOOD funding call (proposal number 114: SUSDIET). The funders had no role in the design, analysis or writing of this article. Conflict of interest: None. Authorship: P.S. and L.C. formulated the research questions and study design. C.L.R.P. carried out the study, analysed the data and wrote the article. Ethics of buman subject participation: Not applicable.

\section{Supplementary material}

To view supplementary material for this article, please visit http://dx.doi.org/10.1017/S1368980016000495

\section{References}

1. Krueger J, Biedrzycki P \& Hoverter SP (2015) Human health impacts of climate change: implications for the practice and law of public health. J Law Med Ethics 43, 79-82.

2. Solomon S, Plattner GK, Knutti R et al. (2009) Irreversible climate change due to carbon dioxide emissions. Proc Natl Acad Sci USA 106, 1704-1709. 
3. Garnett $\mathrm{T}$ (2011) Where are the best opportunities for reducing greenhouse gas emissions in the food system (including the food chain)? Food Policy 36, Suppl. 1, S23-S32.

4. Godfray HCJ, Beddington JR, Crute IR et al. (2010) Food security: the challenge of feeding 9 billion people. Science 327, 812-818.

5. Rayner M (2014) Front-of-pack and point-of-purchase labelling schemes designed for obesity prevention. In Managing and Preventing Obesity: Behavioural Factors and Dietary Interventions, pp. 325-334 [T Gill, editor]. Cambridge: Woodhead Publishing.

6. Vallgårda S, Holm L \& Jensen JD (2014) The Danish tax on saturated fat: why it did not survive. Eur J Clin Nutr 69, 223-226.

7. Scarborough P, Payne C, Agu CG et al. (2013) How important is the choice of the nutrient profile model used to regulate broadcast advertising of foods to children? A comparison using a targeted data set. Eur J Clin Nutr 67, 815-820.

8. Wyness LA, Butriss JL \& Stanner SA (2012) Reducing the population's sodium intake: the UK Food Standards Agency's salt reduction programme. Public Health Nutr 15, 254-261.

9. Jeffries E (2015) Changing course. Nature Clim Change 5, 405-407.

10. Green R, Milner J, Dangour AD et al. (2015) The potential to reduce greenhouse gas emissions in the UK through healthy and realistic dietary change. Clim Change 129, 253-265.

11. Joyce A, Hallett J, Hannelly T et al. (2014) The impact of nutritional choices on global warming and policy implications: examining the link between dietary choices and greenhouse gas emissions. Clin Ophthalmol 8, 2501-2506.

12. Hallström E, Carlsson-Kanyama A \& Börjesson P (2014) Environmental impact of dietary change: a systematic review. J Cleaner Prod 19, 1-11.

13. Auestad N \& Fulgoni VL (2015) What current literature tells us about sustainable diets: emerging research linking dietary patterns, environmental sustainability, and economics. $A d v$ Nutr 6, 19-36.

14. World Health Organization (2015) Healthy Diets. Fact Sheet No. 394. Geneva: WHO; available at http://www.who.int/ mediacentre/factsheets/fs394/en/

15. Caro D, Davis SJ, Bastianoni S et al. (2014) Global and regional trends in greenhouse gas emissions from livestock. Clim Change 126, 203-216.

16. Millward JD \& Garnett T (2010) Food and the planet: nutritional dilemmas of greenhouse gas emission reductions through reduced intakes of meat and dairy foods. Proc Nutr Soc 69, 103-118.

17. Whiting PF, Rutjes AW, Westwood ME et al. (2011) QUADAS-2: a revised tool for the quality assessment of diagnostic accuracy studies. Ann Intern Med 155, 529-536.

18. Biesbroek S, Bueno-de-Mesquita HB, Peeters PH et al. (2014) Reducing our environmental footprint and improving our health: greenhouse gas emission and land use of usual diet and mortality in EPIC-NL: a prospective cohort study. Environ Health 13, 27.
19. Scarborough P, Appleby PN, Mizdrak A et al. (2014) Dietary greenhouse gas emissions of meat-eaters, fish-eaters, vegetarians and vegans in the UK. Clim Change 125, 179-192.

20. Soret S, Mejia A, Batech M et al. (2014) Climate change mitigation and health effects of varied dietary patterns in real-life settings throughout North America. Am J Clin Nutr 100, Suppl. 1, 490S-495S.

21. Tilman D \& Clark M (2014) Global diets link environmental sustainability and human health. Nature 515, 518-522.

22. Vieux F, Soler LG, Touazi D et al. (2013) High nutritional quality is not associated with low greenhouse gas emissions in self-selected diets of French adults. Am J Clin Nutr 97, $569-583$

23. Berners-Lee M, Hoolohan C, Cammack H et al. (2012) The relative greenhouse gas impacts of realistic dietary choices. Energy Policy 43, 184-190.

24. Briggs AD, Kehlbacher A, Tiffin R et al. (2013) Assessing the impact on chronic disease of incorporating the societal cost of greenhouse gases into the price of food: an econometric and comparative risk assessment modelling study. BMJ Open 3, e003543

25. Hallström E, Röös E \& Börjesson P (2014) Sustainable meat consumption: a quantitative analysis of nutritional intake, greenhouse gas emissions and land use from a Swedish perspective. Food Policy 47, 81-90.

26. Hendrie GA, Ridoutt BG, Wiedmann TO et al. (2014) Greenhouse gas emissions and the Australian diet - comparing dietary recommendations with average intakes. Nutrients 6, 289-303.

27. Hoolohan C, Berners-Lee M, McKinstry-West J et al. (2013) Mitigating the greenhouse gas emissions embodied in food through realistic consumer choices. Energy Policy 63, 1065-1074.

28. Milner J, Green R, Dangour AD et al. (2015) Health effects of adopting low greenhouse gas emission diets in the UK. BMJ Open 5, e007364.

29. Meier T \& Christen O (2012) Environmental impacts of dietary recommendations and dietary styles: Germany as an example. Environ Sci Technol 47, 877-888.

30. Temme E, Bakker HME, Brosens MCC et al. (2013) Environmental and nutritional impact of diets with less meat and dairy - modeling studies in Dutch children. Proc Nutr Soc 72, E321.

31. Tukker A, Goldbohm RA, de Koning A et al. (2011) Environmental impacts of changes to healthier diets in Europe. Ecol Econ 70, 1776-1788.

32. van Dooren C, Marinussen M, Blonk H et al. (2014) Exploring dietary guidelines based on ecological and nutritional values: a comparison of six dietary patterns. Food Policy 44, 36-46.

33. Wilson N, Nghiem N, Ni Mhurchu C et al. (2013) Foods and dietary patterns that are healthy, low-cost, and environmentally sustainable: a case study of optimization modeling for New Zealand. PLoS One 8, e59648.

34. Black RE (2014) Global distribution and disease burden related to micronutrient deficiencies. Nestle Nutr Inst Workshop Ser 78, 21-28. 